\title{
Gender Equality and the Empowerment of Women and Girls in Nigeria: The Way Forward to National Security
}

\author{
Adams Oluwadamilola Kemi, Olajumoke Ganiyat Jenyo \\ National Defence College, Abuja, Nigeria \\ Email: lizbethdammy@yahoo.com
}

Received 27 May 2016; accepted 26 July 2016; published 29 July 2016

Copyright @ 2016 by authors and Scientific Research Publishing Inc.

This work is licensed under the Creative Commons Attribution International License (CC BY). http://creativecommons.org/licenses/by/4.0/

(c) (i) Open Access

\begin{abstract}
More essentially, women have been subjected to social control and dominated by men. This is a result of persisting cultural stereotype, misuse of religious and traditional practises in which educational, political and social power are dominated by men, and women have always been followers of men in the society and the men predominantly see themselves as leaders of women. Gender Equality has been a great issue of concern in Nigeria most especially among the women, equality between men and women is just fair and right. The attainment of gender equality is not only seen as an end itself and human right issues, but as a prerequisite for the achievement of sustainable development and national security in Nigeria. To respond to the challenges of gender inequalities, there is a need to recognise the main issues leading to inequality between genders. The research methodology is as termed qualitative research, with the use of primary data gotten through administered questionnaire and secondary data gathered from the news print and journals. The aim of the study was to basically know the major causes of gender inequality in Nigeria. We also suggested strategies to ensure gender equality in all sectors in Nigeria.
\end{abstract}

\section{Keywords}

Gender Equality, Women and Girls, National Security

\section{Background of the Study}

A nation that is not engendered is endangered. Engendering a country through gender equality implies the effectiveness of National Security that promotes greater equality between women and men. Gender is a central organising principle of societies and often governs the processes of security. Women represent over $70 \%$ of the 
World's poor due to unequal access to economic opportunities. Increasing female participation in the workforce and the development of the female human capital will not only help to reduce poverty at the household level, it will also radically enhance national security [1].

The global economic recession and the gulf between job creation and the growth in the numbers of job seekers have worsened the employment situation for women and men alike. But women face greater vulnerabilities in the labour market because of their relative lack of education and training, the tendency to channel women into certain occupations, and the continuous heavy burdens of unpaid domestic work, childbearing and childcare, which restrict the time and energy available for income-earning activities.

Nigeria like other countries in the world is responding to the clear request calls made variously by the United Nations societies of all forms of discriminations especially gender based discriminations. Nigeria indeed has tried to respond to this development from the international arena by articulating policies and programmes that seek to reduce gender in equalities in socio economic and political spheres, however, the success of bridging the gap between men and women is farfetched [2].

[3] opines that: politically, Nigeria women are negligible and undermined force. Economically, they constitute the majority of the peasant labour force in the agricultural sector, while most of the others occupy the bottom of occupational ladder and continue to be channelled into service and domestic occupations. The consequence of the unequal status between men and women is high level of economics and political powerlessness among women, and powerlessness in turn retards development of any level, politically, economically and socially. Gender based discrimination is an all pervasive global problem which has occasioned intense gender inequality in many countries of the world. It existed from the dawn of civilization and has continued over centuries. Gender discrimination has created wide gender gaps in many countries of the world, with very devastating social, economic and, health consequences on the members of the female gender, who have been intensely marginalized, and subjugated to the background. The world, for the past few decades, has witnessed a resurgent interest in feminist jurisprudence. This interest has culminated in the emergence of numerous global strategies geared towards women empowerment and emancipation [4].

The Nigerian culture perceives and treats men as superior to women, this is well manifested in the "son preference syndrome" that is prevalent in Nigeria. Male children in Nigeria often enjoy preferential treatment, like exemption from house chores; they enjoy unlimited right to education, while the girls are trafficked by some greedy parents for economic gains in the home. The culture equally disinherits wives and daughters. In the home front, women are subjected to all sorts of inhuman and degrading treatment. Our culture strictly restricts women to the stereotyped role of home keeping, childbearing and childrearing. She is to be seen and not heard. [5] has rightly observed that this subordination of women by our culture knows no boundaries or barriers, and is not dependent on the "social, educational or economic status of the Nigerian women. Consequently, one finds that uneducated and poor women in the rural community suffer as much subordination as educated and rich women in the urban centre". Another worrisome aspect of this cultural marginalization of women in Nigeria as observed earlier is its deep rooted nature in the Nigerian system [6].

\section{Statement of the Problem}

An emerging contemporary security challenges been faced by Nigerians today is the use of females as suicide bombers and kidnappers in public places such as markets and places of worship (Mosque and Churches) by the terrorist group (Boko haram) in the Northern part of Nigeria as well as the Niger Delta Militant in the South South part of Nigeria, Armed robbery and political violence and instability as it is presently all over the country now.

Several reasons have been the cause of these challenges. These include gender inequality, high rate of poverty and illiteracy among Nigerian women due to some religious and cultural beliefs.

In an interview, Tinubu also observed that Men have always been a very dominant character, the women find it difficult to know where they are placed, men expect women to even beg for their own right, gender equality can be achieved in Nigeria but the country has a very long way to go [7].

At the heat of the problem is the Absence of a Comprehensive strategy for promoting gender equality and empowering girls as an approach to addressing national security issues.

It is against this background that this study seeks to find answer to the following research questions. 


\section{Research Questions}

1) What is the relationship between Gender Equality and National Security?

2) What are the factors responsible for gender inequality in Nigeria?

3) What are the prospects for achieving National security through Gender Equality and the Empowerment of Women and Girls in Nigeria?

4) What are the strategies for promoting gender equality in Nigeria as means of enhancing national security?

\section{Objectives of the Study}

The main objective of this study is to examine how gender equality and women empowerment can impact on Nigeria's national security and the specific objectives are:

1) To determine the relationship between gender equality and national security;

2) To determine the factors responsible for gender inequality in Nigeria;

3) To assess the ways in which national security can be achieved through gender equality and the empowerment of women and girls in Nigeria and

4) To proffer comprehensive strategies that can be used to promote gender equality in Nigeria as a way forward towards enhanced National Security.

\section{Scope of the Study}

The essence of this research work is to primarily study Gender equality in Nigeria and how it can impact on National security of Nigeria. The research intends to focus on 12 states representing the 6 geopolitical zones of Nigeria for easy analysis of data. This will reduce cost and avoid complexity that may arise as a result of having a very large population.

\section{Conceptual Clarifications and Literature Review}

We shall clarify some concepts and review some literature with regards to developing the subject in Nigeria.

Gender: This refers to social roles allocated respectively to men and women in particular societies and at particular times. Such roles and the differences between them are conditioned by a variety of political, economic, ideological and cultural factors, and are characterized in most societies by unequal power relations [8]. [9] opines that gender constitutes one of the determinants of how poverty is experienced and of wealth creation. Rights and entitlements of men and women to opportunities, resources and decision making are based on socio-cultural norms rather than on human rights or the respective development capability of men and women.

[10] defines gender as a system of roles relationship between women and men that are determine not biologically but by the social, political and economic context. [11] captures the nature of gender, thus: Gender is the social organization of sexual differences but, this does not means that gender reflects or implements fixed and natural physical differences between women and men, rather gender is the knowledge that establishes meaning for bodily differences. These meaning vary across cultures, social groups and time since nothing about the body including women's reproductive organs, determines univocally how social division will be shaped.

Women: Refers to the female gender, the opposite of male gender. There is the dependency syndrome that women are known to have being dependent on men. In order words, their roles are that of helpers to men [12].

Gender equality: This refers to a situation where women and men have equal conditions for realising their full human rights and potentials; are able to contribute equally to national, political, economic, social and cultural development and benefit equally from the results. Furthermore, it entails that the underlying causes of discrimination are systematically identified and removed in order to give men and women equal opportunities. Equality is therefore understood to include both formal equality and substantive equality, and not merely simple equality to men [13].

National Security: National security is a concept that a government, along with its parliaments, should protect the state and its citizens against all kind of "national" crisis through a variety of power projections, such as political power, diplomacy, economic power, military might, and so on [14]. 


\section{Research Methodology}

\subsection{Method of Data Collection}

The study adopted both primary and secondary sources of data, this involve wide consultation of books, journals, magazines, internet, published and unpublished books. Unstructured interview with some legislators and security personnel's was conducted. Data was also collected using the questionnaire which the researcher administered face to face to the respondents. Out of 300 copies of questionnaire distributed to the respondents, 280 copies were retrieved. This represented a response rate of $93.3 \%$.

\subsection{Sampling Technique}

Using the simple random sampling technique, five different states were visited which include Kwara, Kaduna, Ondo, Nassarawa, Rivers and the FCT. Using the purposive sampling technique, the researcher purposively selected a sample size of 300 respondents from the five states and the FCT. Each state contributed different indigene from the 36 states and the FCT. 2 states each were selected from the 6 Geopolitical zones of Nigeria sample sizes, thereby selecting 10 males and 10 females from each of the 12 states selected Therefore, the sample size for the study were 240 respondents.

\subsection{Analytical Techniques}

- Correlation analysis.

- Descriptive statistics.

\subsection{Data Presentation and Analysis}

\subsubsection{Analysis of Demographic Survey}

$50 \%$ of the respondents are women while $50 \%$ were men, $45 \%$ of the respondents were civil servant, $20 \%$ were military officers, $20 \%$ were private business owners and $15 \%$ were student and corpers, $50 \%$ of the respondent are from North and another $50 \%$ from the south, $51 \%$ were Muslims and $49 \%$ Christians.

\subsubsection{Analysis of Data Survey}

Table 1(a) and Table 1(b) show the distribution of Nigerian peoples perspectives about gender equality.

Table 1. (a) Distribution of Nigerian peoples perspectives about gender equality. (b) Distribution of Nigerian peoples perspectives about gender equality.

(a)

\begin{tabular}{ccccccc}
\hline STATES & Ondo & Ekiti & Rivers & Edo & Enugu & Imo \\
MALE & $\mathbf{4}$ & $\mathbf{8}$ & $\mathbf{5}$ & $\mathbf{8}$ & $\mathbf{5}$ & $\mathbf{5}$ \\
FEMALE & $\mathbf{9}$ & $\mathbf{5}$ & $\mathbf{9}$ & $\mathbf{5}$ & $\mathbf{1 0}$ & $\mathbf{9}$ \\
Average total for SW & \multicolumn{2}{c}{$\mathrm{M}=45 \%$} & S.S M $=50 \%$ & $\mathrm{M}=50 \%$ \\
Average total for South & \multicolumn{2}{c}{$\mathrm{F}=85 \%$} & $\mathrm{~F}=85 \%$ & $\mathrm{~F}=95 \%$ \\
\end{tabular}

(b)

\begin{tabular}{ccccccc}
\hline STATES & Kaduna & Kano & FCT & KWARA & ADAMAWA & BORNO \\
MALE & $\mathbf{2}$ & $\mathbf{2}$ & $\mathbf{3}$ & $\mathbf{1}$ & $\mathbf{1}$ & $\mathbf{4}$ \\
FEMALE & $\mathbf{5}$ & $\mathbf{4}$ & $\mathbf{6}$ & $\mathbf{5}$ & NE Male $=5 \%$ \\
Average total for NW & Male $=20 \%$ & NS Male $=20 \%$ & Female $=30 \%$ \\
Average total for North & Female $=45 \%$ & Female $=55 \%$ & \\
$\begin{array}{c}\text { Average total for Nigeria } \\
\text { (North and South) }\end{array}$ & \multicolumn{7}{c}{ Male $=15 \%$, Female $=43.3 \%$} \\
\hline
\end{tabular}


Nigerian peoples' perspectives about gender equality are shown in Figure 1(a) and Figure 1(b). Figure 2 shows different professions Nigerian women in various sectors. Reasons why women should not be equal with men are shown in Figure 3. Figure 4 indicates the religious belief why there can't be gender equality. Ways in which Women causes insecurity in Nigeria are shown in Figure 5.

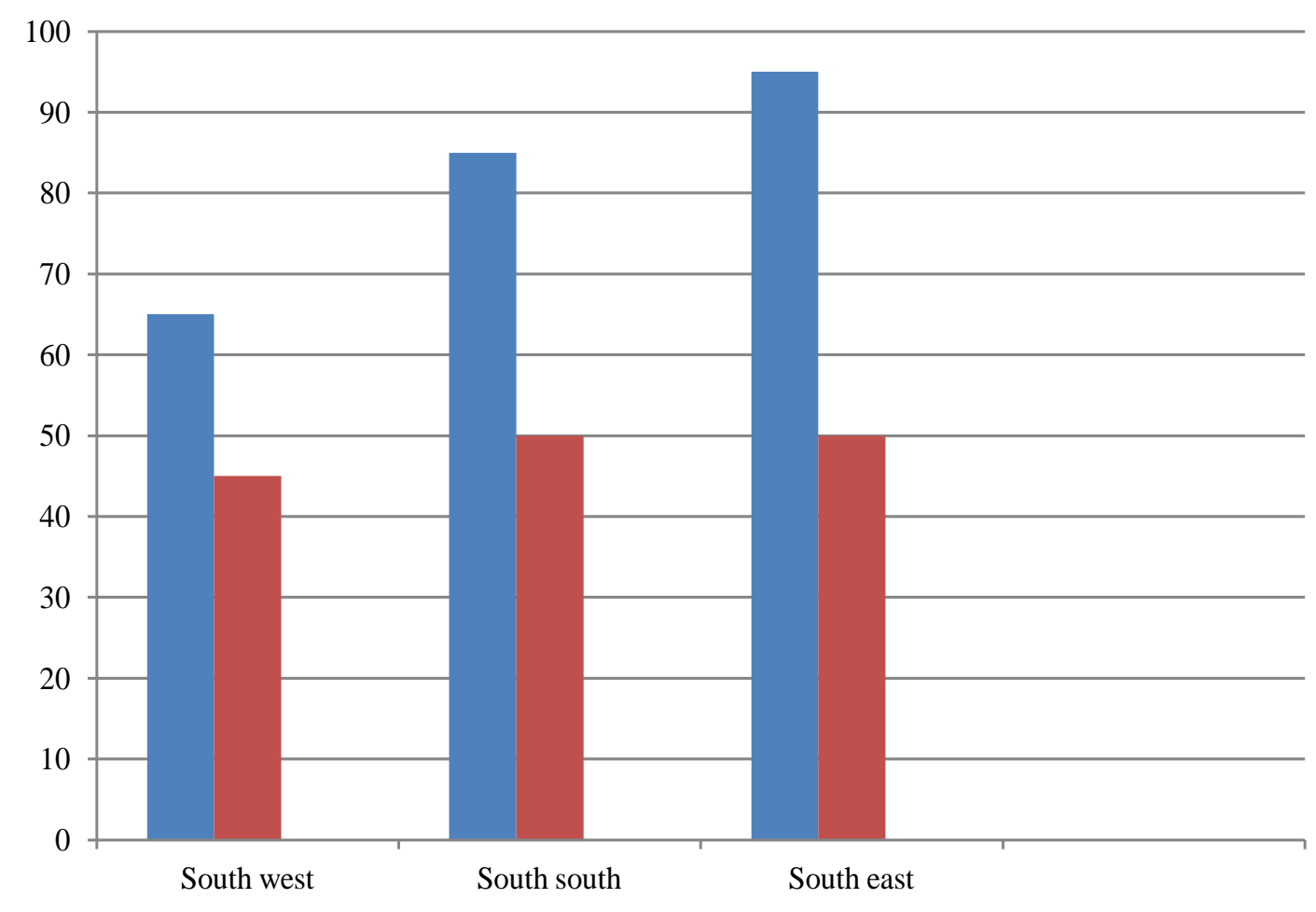

Female

Male

(a)

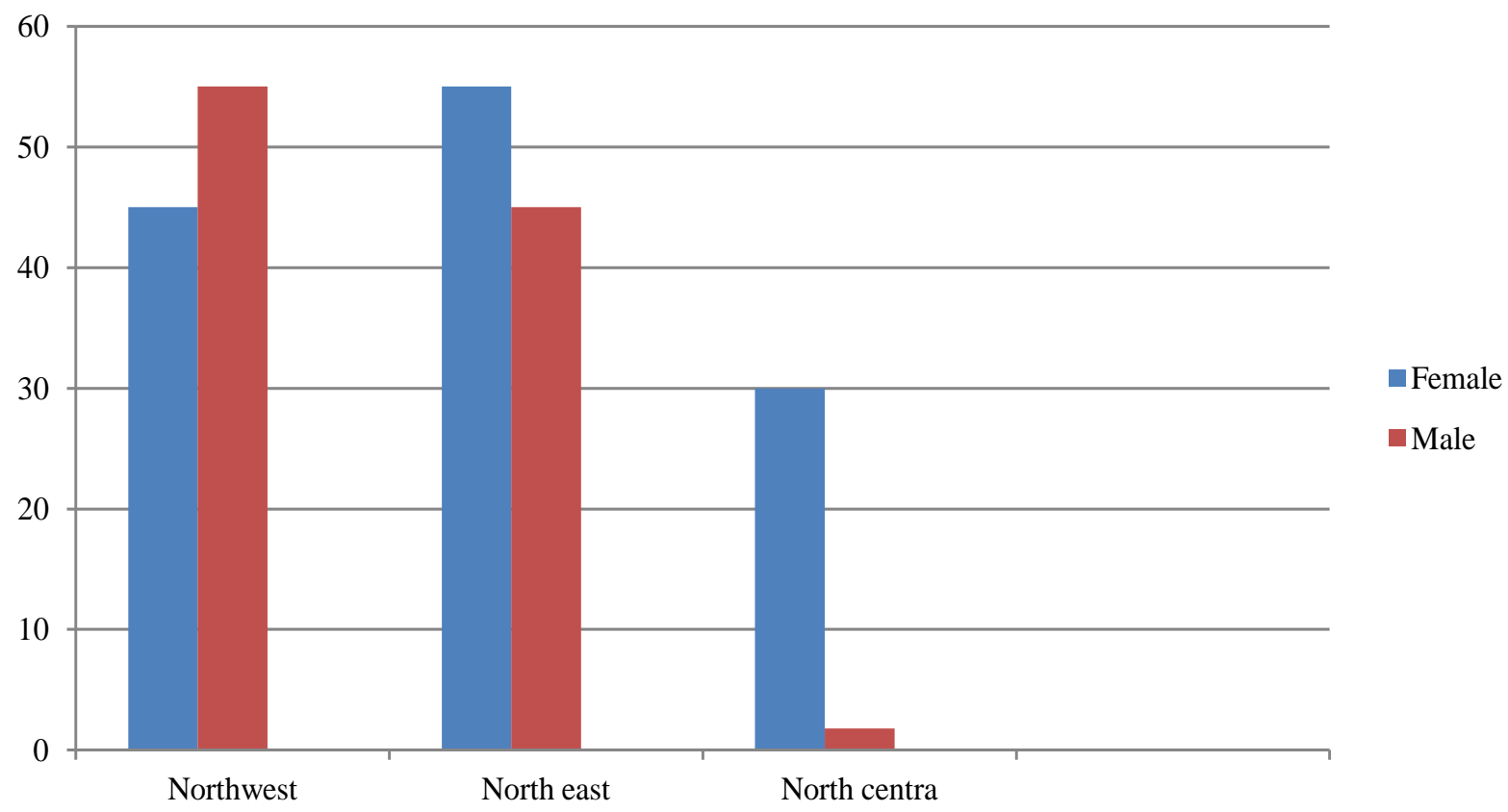

(b)

Figure 1. (a) Graphical notation of Nigerian peoples perspectives about gender equality. (b) Graphical notation of Nigerian peoples perspectives about gender equality. Source: Field survey, 2015. 


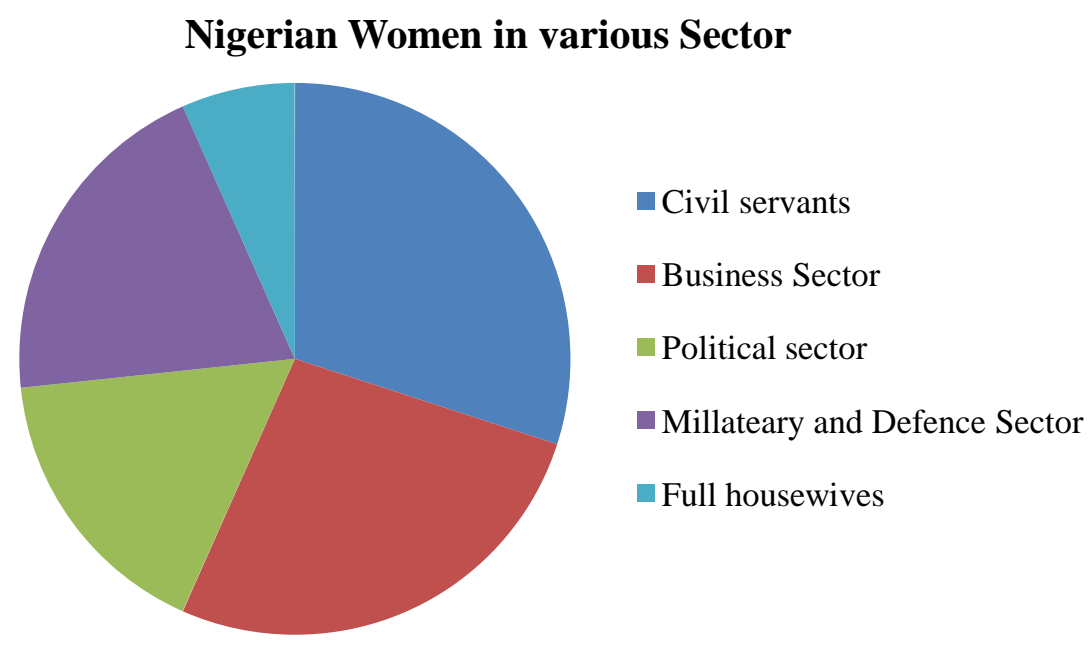

Figure 2. Graphical notation of Nigerian women in various sectors. Source: Field survey, 2015.

\section{Reasons why women should not be equal with men}

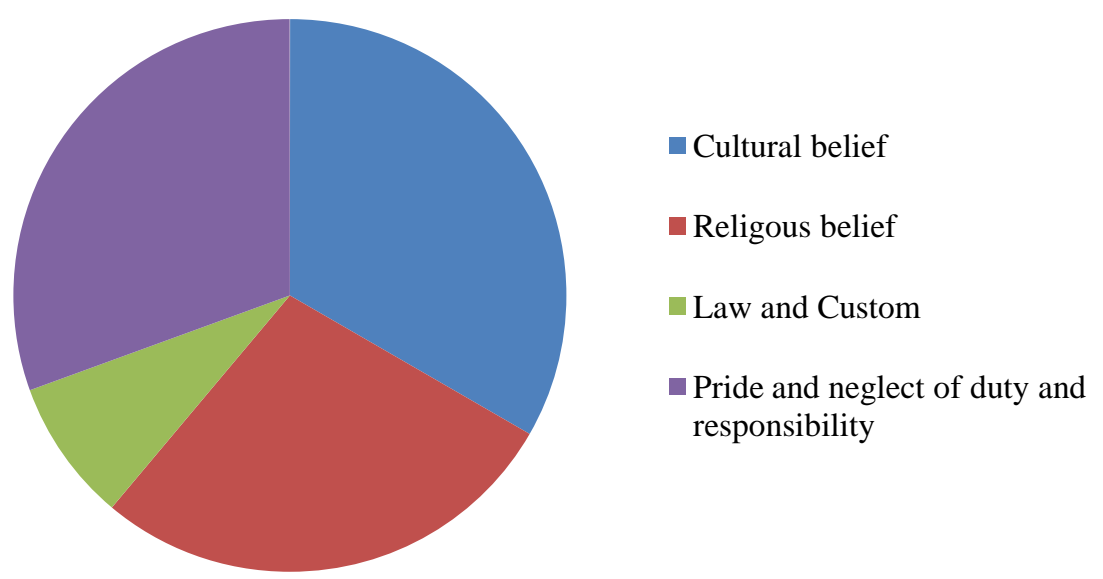

Figure 3. Graphical notation on reasons why women should not be equal with men. Source: Field survey, 2015.

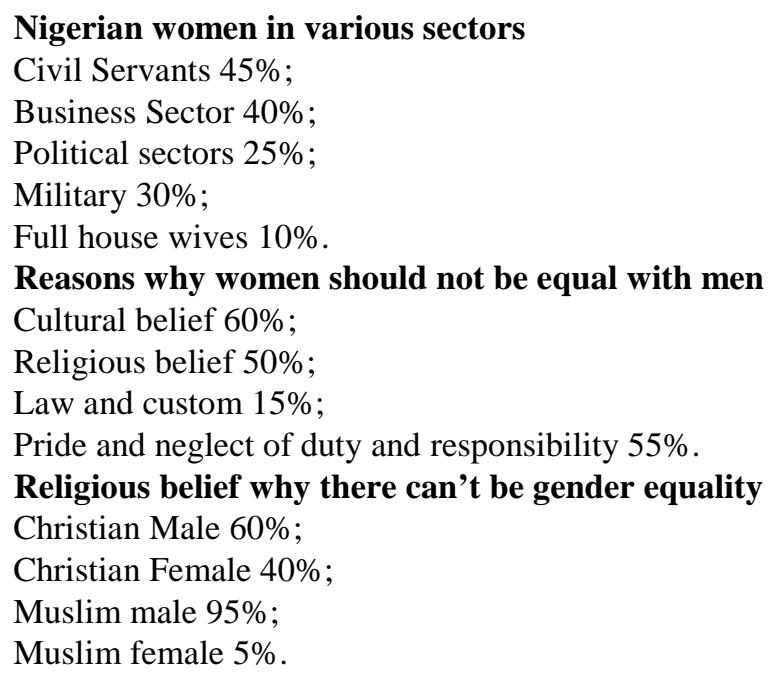




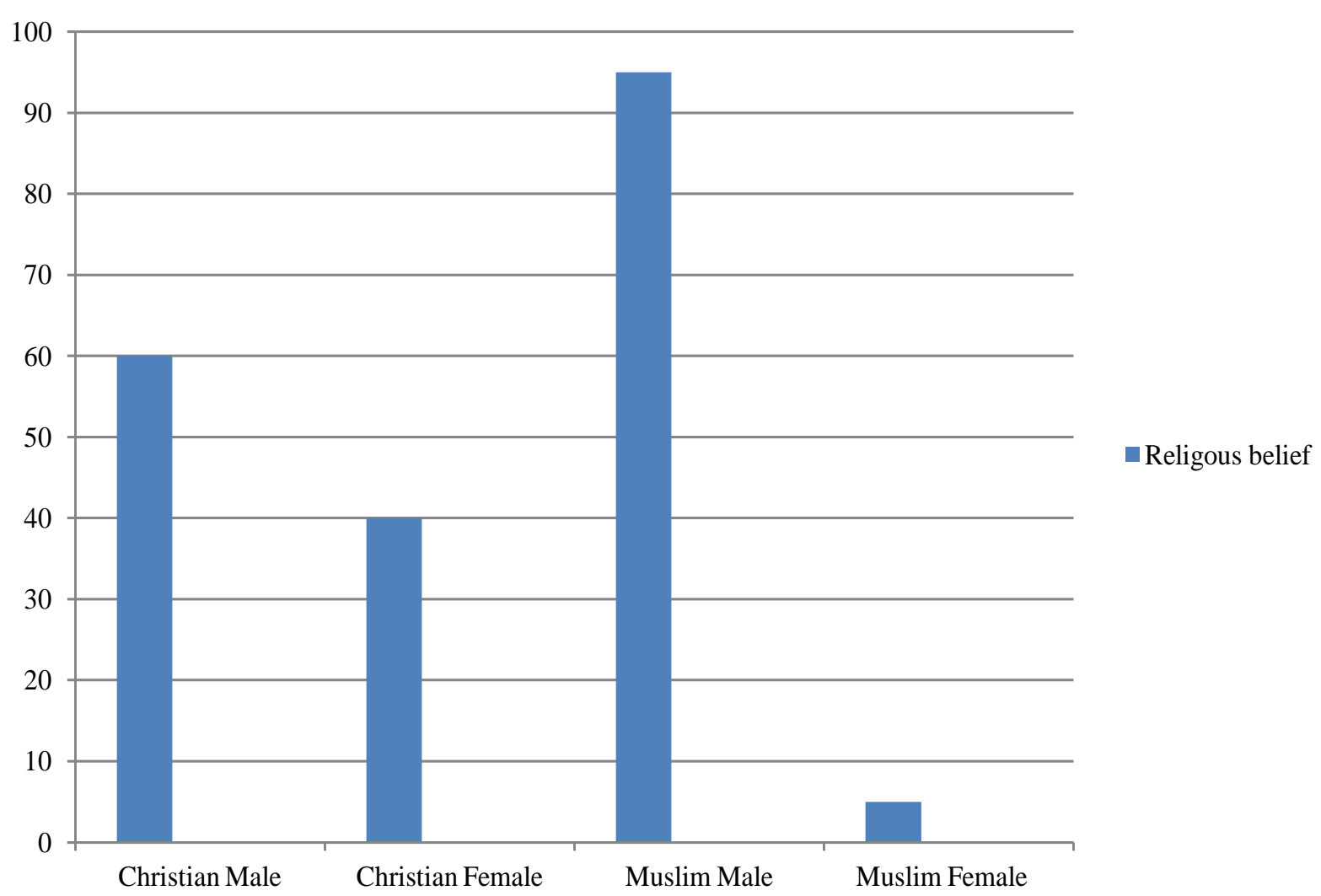

Figure 4. Graphical notation on religious belief why there can’t be gender equality. Source: Field survey, 2015.

\section{Ways in which Women Causes Insecurity In Nigeria}

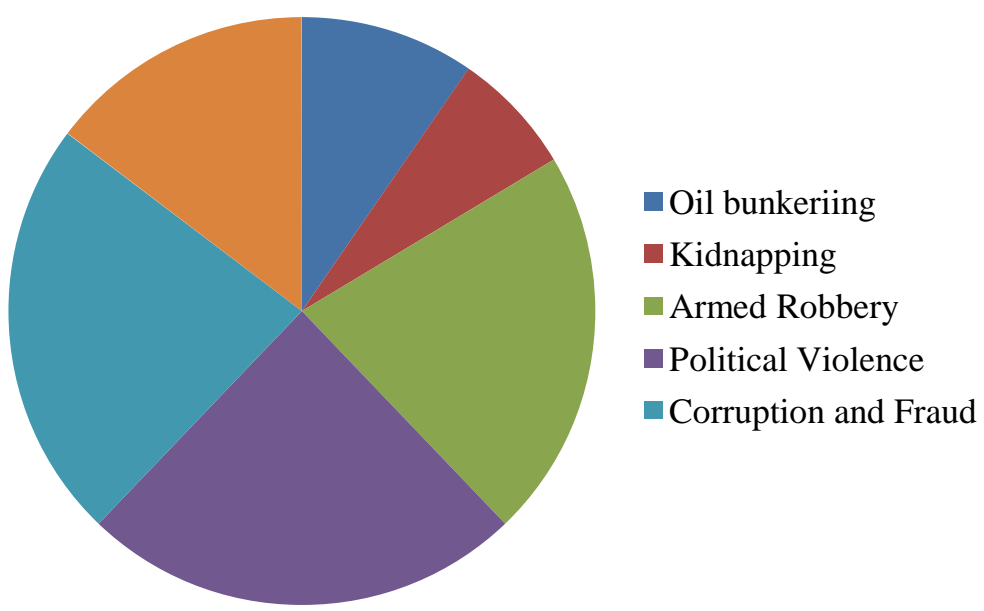

Figure 5. Graphical notation of ways in which women causes insecurity in Nigeria. Source: Field survey, 2015.

Ways in which women causes insecurity in Nigeria

- Boko Haram suicide bombing in the North 26\%;

- Oil bunkering in the Niger Delta region $17 \%$;

- Kidnapping in the South 12\%;

- Armed robbery in the South 38\%;

- Political violence and instability all over Nigeria $43 \%$;

- Corruption $41 \%$. 


\section{Summary of the Findings}

The following findings were made:

1) Religious and cultural beliefs are the major causes of gender inequality in Nigeria.

2) The major strategy to promote gender equality is to create awareness of everyone to the benefit that can drive national development through gender equality.

3) The major ways to promote National security through gender equality and the empowerment of women and girls is education and more empowerment through poverty alleviation programmes and also to create awareness of everyone to the benefit that can drive national security through gender equality.

4) Women are more in civil service jobs like Nurses, Teachers, Secretaries and etc than other sector in the Nigerian economy.

5) From the analysis of the study southern women are the major set of people who want gender equality in Nigeria.

Strategies to achieve National Security through Gender Equality and the Empowerment of Women and

\section{Girls in Nigeria}

For the purpose of this research some strategies were derived from the result of the analysis of the study. These include:

- Educational Empowerment of Women,

- Economic Empowerment of Women,

- More Political Appointment for Women,

- Awareness should be made to everyone on the benefit of gender equality as it relates to National Security in Nigeria,

- Women should be more confident, know their right, and believe there is nothing they can't achieve,

- Men should start accepting the fact that both genders are equal and should be given same treatment everywhere at all time.

\section{Conclusion and Recommendations}

\subsection{Conclusion}

This paper has examined the issue of gender inequality and the empowerment of women and girls in Nigeria and its effect on national security.

Some issues that are central to women and national security include high rate of poverty and illiteracy, culture and religious belief. All these constitute a major source of insecurity in Nigeria.

It is quite glaring that gender equality implies equal rights, opportunities, and treatment for women and men, girls and boys in all spheres of life. It equally implies that both men and women are free to develop their personal abilities and make choices without the limitations. If women are well empowered and have proper orientation about life and what it takes to become whatever they want to be irrespective of their gender, religion and culture, then it will be difficult for any evil group to use them to perpetrate their evil deeds thereby enhancing national security.

Nigeria is therefore called upon to be part of global trend towards gender equality although significant strides have been made in many countries of the world to bridge gender gaps, and advance gender equality, in compliance with the demands of international instruments on women's right, most countries like Nigeria are still lagging behind especially in strategic positions [15], for example, women in the upper chamber of the National Assembly is 7 out of 109 Senators and 14 in the Green Chamber of 360 Legislature, altogether which is equivalent to $4.4 \%$ of the whole National Assembly. So also the Federal Executive Council has 3 Women out of 36 Ministers which is just $8.3 \%$.

Nigeria cannot afford to continue to treat half of its population and a significant part of the productive force as inferior being. We need to give our women the full chance to participate in all sectors of society. The roles of women as house makers cannot be down played. To achieve gender equality in Nigeria, economic and political powerlessness of women must be addressed. Our governments should therefore realize that intelligence and ability are more relevant in solving the problem of any society or nation than gender classification [16]. Giving women equal right of participation in the scheme of things will in no small measure engender a meaningful and sustainable national (and global) development thereby enhancing national security. 
Gone should be the days when we say "Behind every successful man there must be a woman rather we should see this as "Beside every successful man there should be a successful woman".

\subsection{Recommendations}

The problem of gender inequality in Nigeria is further compounded by weak institutional capacities and insufficient prioritisation of resources which undermine the effectiveness of existing laws and efforts. Therefore, in terms of the link between gender equality and national security, empowerment of women and girls needs to be prioritised in national and regional development agendas [1].

Hence, some recommendations were derived from this study:

\section{An urgent Review of all Gender Discriminatory Laws in Nigeria}

Nigerian government should endeavour to review all gender discriminatory laws that still exist in the pages of our statute books in order to demonstrate her total commitment to eradicate gender inequality in Nigeria.

\section{Uprooting of all Obnoxious Traditional Practices that Impede the Rights of Women}

The Nigerian government should collaborate with traditional rulers in Nigeria and other stakeholders to ensure that all harmful and traditional practices which target only women, are uprooted.

\section{Economic Empowerment of Women}

It is high time Nigerian government increased women's presence at the labour market by granting women more loan to start up businesses to reduce poverty and insecurity level in Nigeria [7].

\section{More Educational Empowerment for Women}

Compulsory girl-child education which Nigeria has already adopted should be enforced and sustained.

\section{More Political Appointment for Women}

Nigerian government is called upon to beef up her political appointive positions for women. The present appointments still fall short of the international expectation, that 35 per cent of all political appointment should be reserved for women.

\section{Enactment of Female Based Specific Law}

It is apparent from this discourse that there is every need to enact gender specific laws to curb gender violence.

\section{The Role of the Media.}

The government should use the media to devise more effective awareness raising programmes for women especially in the grassroots.

\section{Establishment of More Internet Portals to Foster Dialogue for the Promotion of Gender Equality.}

This portal will create an avenue of reaching out to the public or the internet, by fostering a dialogue on the importance of gender equality.

\section{References}

[1] Africa Development Bank (2012) Demographic Dividend or Time Bomb. Tunis, Belvedere Tunisia.

[2] Olurode, L. (2011) In the Paper Titled: State and Political Participation. Gender Analysis of Nigeria, 2011 Elections.

[3] Omonubi, M.M. (2003) Gender inequality in Nigeria. Spectrum, Ibadan.

[4] UNESCO (1999) Unit for the Promotion of the Status of Women and Gender Equality. Paris, 6.

[5] Federal Ministry of Women Affairs and Child Development (2006) National Gender Policy, Situation Analysis and Framework. Abuja.

[6] Onyejekwe, C. (2011) Women and Politics in Nigeria. J. Res. Devel, 3, 1-12.

[7] Tinubu, U. (2016) Interviewed on Gender Issues and Women Empowerment on 15 February 2016 at Abuja.

[8] Onabu, J.O. (2006) Nigeria Must Embrace Gender Equality. This Day, 6, 9-22.

[9] LEDAP (2003) Gender Issues. A Quarterly Publication of Women, Human Right Programme of Legal Defence and Assistance Project, Vol. 2, No. 2, September.

[10] CIRDDOC (2001) Gender and Politics in Nigeria. CIRDDOC Public Education Series, No. 5, Fourth Dimension Publ, Enugu, 1.

[11] Longwe (1991) Gender Equality and Women’s Empowerment. UNICEF, New York.

[12] Aina, O. (1998) Women, Culture and Society. In: Sesay, A. and Odebiyi, A., Eds., Nigerian Women in Society and Development, Dokun Publishing House, Ibadan. 
[13] Elegbede, T. (2012) Gender Inequality: The Nigerian Case. Nigerian Master Web Citizen.

[14] Onuma, U. (2015) Interviewed on Gender Issues and Women Empowerment on 3 February 2016 at Abuja.

[15] Awe, B. (1995) Women Political Participation, Why the Barrier. Daily Times, $31^{\text {st }}$ October.

[16] Nda, L.H. (2003) Women in the Power Equation of Nigerian Politics. Dat and Partners Logistic Ltd., Lagos. 


\section{National Defence College Dept. of Science and Tech}

This questionnaire is designed to obtain information on gender equality and the empowerment of women and girls in Nigeria-the way forward to national security, it is purely for academic purpose and all information supplied will be treated confidentially to be completed by the respondents.

Tick ( ) or Complete as appropriate

1. Sex

Female ( ) Male ( )

2. What is your State?

3. What is your occupation?

4. What is your age bracket?
$15-30()$
$30-60(\quad)$
60 \& above ( )

5 . What religion do you practice?

Christianity ( ) Muslim ( ) Others (specify)

6. Which child do you prefer most?

Female ( ) Male ( ) Neutral ( )

7. Would you have preferred if you are the opposite sex?

Yes ( ) No ( )

8. Do you believe in gender equality?

Yes ( ) No ( )

9. Can you allow your wife to hold a higher position than yours?

Yes ( ) No ( )

10. Will you agree with your husband if he disallowed you from holding a certain high position?

Yes ( ) No ( )

11. Do you think Governance in Nigeria is gender equal?

Yes ( ) No ( )

12. Which of this would you not allow your female child or wife to become?
Politician ( )
Soldier ( )
pilot ( ) sailor ( )
Medical Doctor ( ) lawyer ( ) others (specify).

13. Why do you think women should not be high position?

1) It makes them neglect their role as a woman at home? ( )

2) It makes them feel superior and proud to their husband? ( )

3) Women are supposed to be at home cooking and taking care of kids and husband ( )

14. What is the major way in which you think women has caused Insecurity in Nigeria? Boko Haram Suicide
Bombing ( )
Illegal Oil Bunkering ( )
Kidnapping ( )
Armed Robbery ( )
Political Violence ( )
Corruption ( )

15. In what way do you think National security can be achieved through gender equality in Nigeria?

Educational Empowerment of Women ( )

Economic Empowerment of Women ( )

Establishment of More Gender Violation Monitoring Agencies ( )

More Political Appointment for Women ( )

16. In how many years to come do you see gender equality coming to reality in Nigeria? 


\section{Submit or recommend next manuscript to SCIRP and we will provide best service for you:}

Accepting pre-submission inquiries through Email, Facebook, LinkedIn, Twitter, etc.

A wide selection of journals (inclusive of 9 subjects, more than 200 journals)

Providing 24-hour high-quality service

User-friendly online submission system

Fair and swift peer-review system

Efficient typesetting and proofreading procedure

Display of the result of downloads and visits, as well as the number of cited articles

Maximum dissemination of your research work

Submit your manuscript at: http://papersubmission.scirp.org/ 